\title{
A study on epidemiology of foot injuries in South Indian population at a tertiary care centre
}

\author{
Gopisankar Balaji*, Sandeep Nema, Anand Kumar
}

Department of Orthopaedics, JIPMER, Pondicherry, India

Received: 01 July 2020

Revised: 02 August 2020

Accepted: 03 August 2020

\author{
*Correspondence: \\ Dr. Gopisankar Balaji, \\ E-mail: drgopi9596@gmail.com
}

Copyright: () the author(s), publisher and licensee Medip Academy. This is an open-access article distributed under the terms of the Creative Commons Attribution Non-Commercial License, which permits unrestricted non-commercial use, distribution, and reproduction in any medium, provided the original work is properly cited.

\begin{abstract}
Background: Knowledge of the epidemiology of foot injuries might be useful for implementing injury prevention programmes and for academic research purpose.

Methods: This retrospective descriptive study was conducted on patients presenting with foot injuries to our emergency medical service department from May 2018 to April 2019.

Results: Total 604 foot injuries were available for final evaluation. There were 461 male and 131 female patients. The mean age was 32.09 years. The commonest mode of injury was road traffic accident. Total 192 feet had only soft tissue injuries while 412 had bony injuries. Total 140 of 323 cases of forefoot injuries were due to metatarsal fractures followed by 63 cases of proximal phalanx fractures. Among the midfoot injuries, Lisfranc fracture dislocation was more common accounting for 12 out of 38 cases. Calcaneal fractures were more common among hindfoot injuries accounting for 27 out of 45 cases.

Conclusions: To conclude, foot injuries account for $13.4 \%$ of all musculoskeletal injuries. $68.2 \%$ accounts for bony injuries. Among foot bony injuries, forefoot injuries (78.4\%) are more common.
\end{abstract}

Keywords: Epidemiology, Fracture, Foot, Injury, Trauma

\section{INTRODUCTION}

Foot injuries (FI) constitute both clinical and psychological challenge to the patient and the treating surgeon due to its complex anatomy. Rapid urbanisation, increase in motor vehicles, high speed travels and road congestion has led to an increase in road traffic accidents. The demographic pattern of foot trauma varies worldwide.

The difference in distribution is multifactorial. These factors are age, location, occupation, industrialization etc. Epidemiology of FI has been reported earlier but most of these studies have reported epidemiology of FI among specific population. These include FI sustained in a particular sports orspecific mechanism of injury. ${ }^{1-3}$ Little has been reported about the epidemiology in general population. $^{4,5}$

The aim of this study is to report the epidemiological distribution of FI among patients presenting to a tertiary care referral centre in South India.

\section{METHODS}

This retrospective cohort study was conducted on patients presenting with FI to the emergency medical service department at Jawaharlal Institute of Postgraduate Medical Education and Research (JIPMER), Puducherry from May 2016 to April 2017. 
This study was approved by the Institute ethics committee. We analyzed the Orthopaedic trauma registry for cases of foot trauma.

All patients with foot injuries during the study period were included in the study. The variables recorded were age, sex, mode of injury, side involved, type of injury (open or closed), soft tissue or bony injury and associated injuries.

All the data collected were entered into the datasheet and analysed using SPSS software package (IBM Corp. Released 2010. IBM SPSS Statistics for Windows, Version 19.0. Armonk, NY: IBM Corp.).

\section{RESULTS}

Total 4417 patients attended Orthopedic emergency during the study period. Among 592 (13.4\%) patients had foot injuries. $12(0.1 \%)$ had bilateral foot injuries.

Thus, 604 feet were available for final evaluation. There were 461 male and 131 female patients. The mean age was 32.09 years (Range: 2 -76 years) (Figure 1).

The commonest mode of injury was road traffic accident which accounted for 357 cases followed by accidental slip and fall in 111 cases, fall of heavy object in 47, fall from height in 41, hit against heavy object in 16 and other modalities in 19 cases (Table 1 ).
Table 1: Various mechanisms of injury.

\begin{tabular}{|ll|}
\hline Mode of injury & No. of patients \\
\hline Road traffic accident & 357 \\
\hline Slip and fall accidentally & 111 \\
\hline Heavy object fall & 48 \\
\hline Fall from height & 41 \\
\hline Hit against heavy object & 16 \\
\hline Assault/ cut injury & 6 \\
\hline Cow stampede & 4 \\
\hline Wheel spoke injury & 3 \\
\hline Machine injury & 3 \\
\hline Train accident & 2 \\
\hline Cracker blast & 1 \\
\hline
\end{tabular}

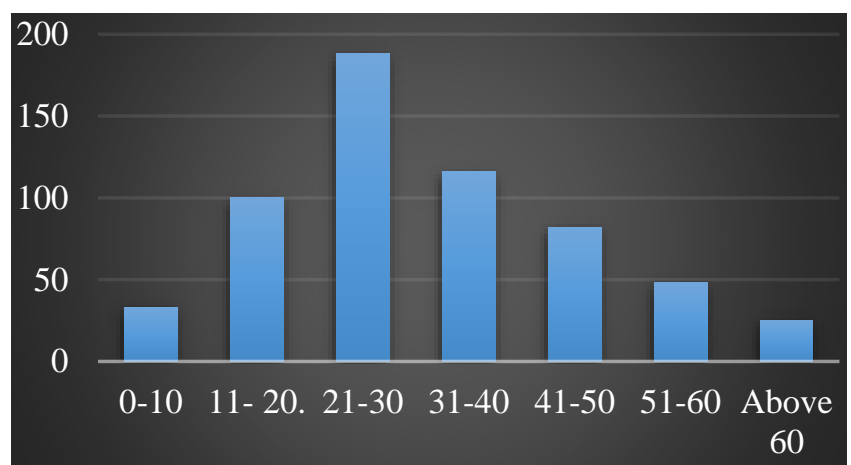

Figure 1: Age (in years) distribution of patients.

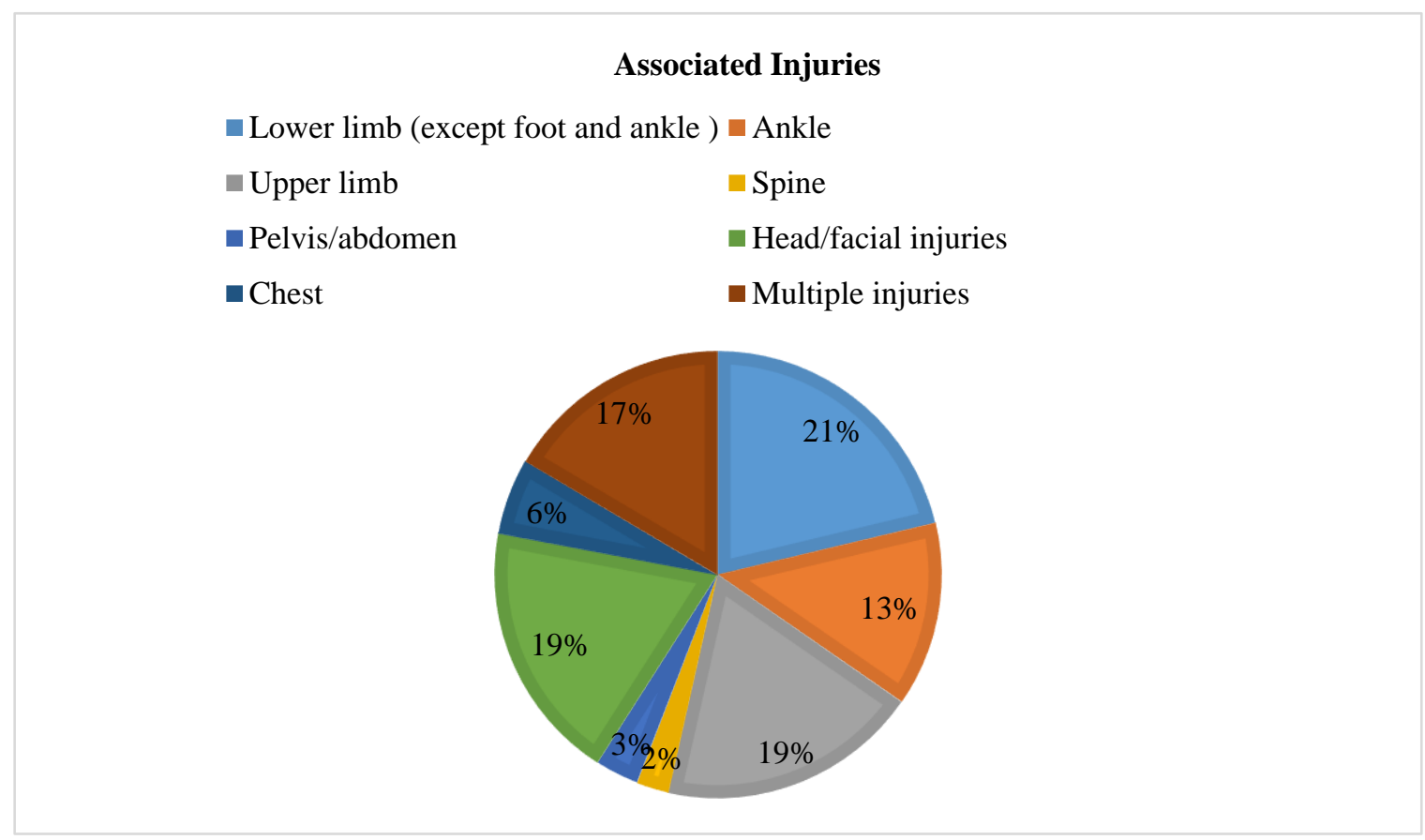

Figure 2: Number of patients with associated injuries.

Among the cases of road traffic accident, 291 were involved in vehicle collision, 48 sustained injury following self- fall from two wheelers and 18 had a run over injury. Right foot was injured in 331 cases and left 
foot in 249. Both feet were injured in 12 cases. 127 cases had associated injuries (Figure 2). Open injuries accounted for 249 feet while 355 were closed injuries. 192 feet had soft tissue injuries while 412 had bony injuries (Figure 3). Of the 192 feet with soft tissue injuries, 53 had open injuries and 139 had closed injuries (Figure 4). Of the 412 feet with bony injuries, 196 were open and 216 were closed. There were 323 forefoot followed by 45 hindfoot, 38 midfoot and 6 combined midfoot and forefoot injuries. 140 of 323 cases of forefoot injuries were due to metatarsal fractures followed by 63 cases of proximal phalanx fractures (Table 2).

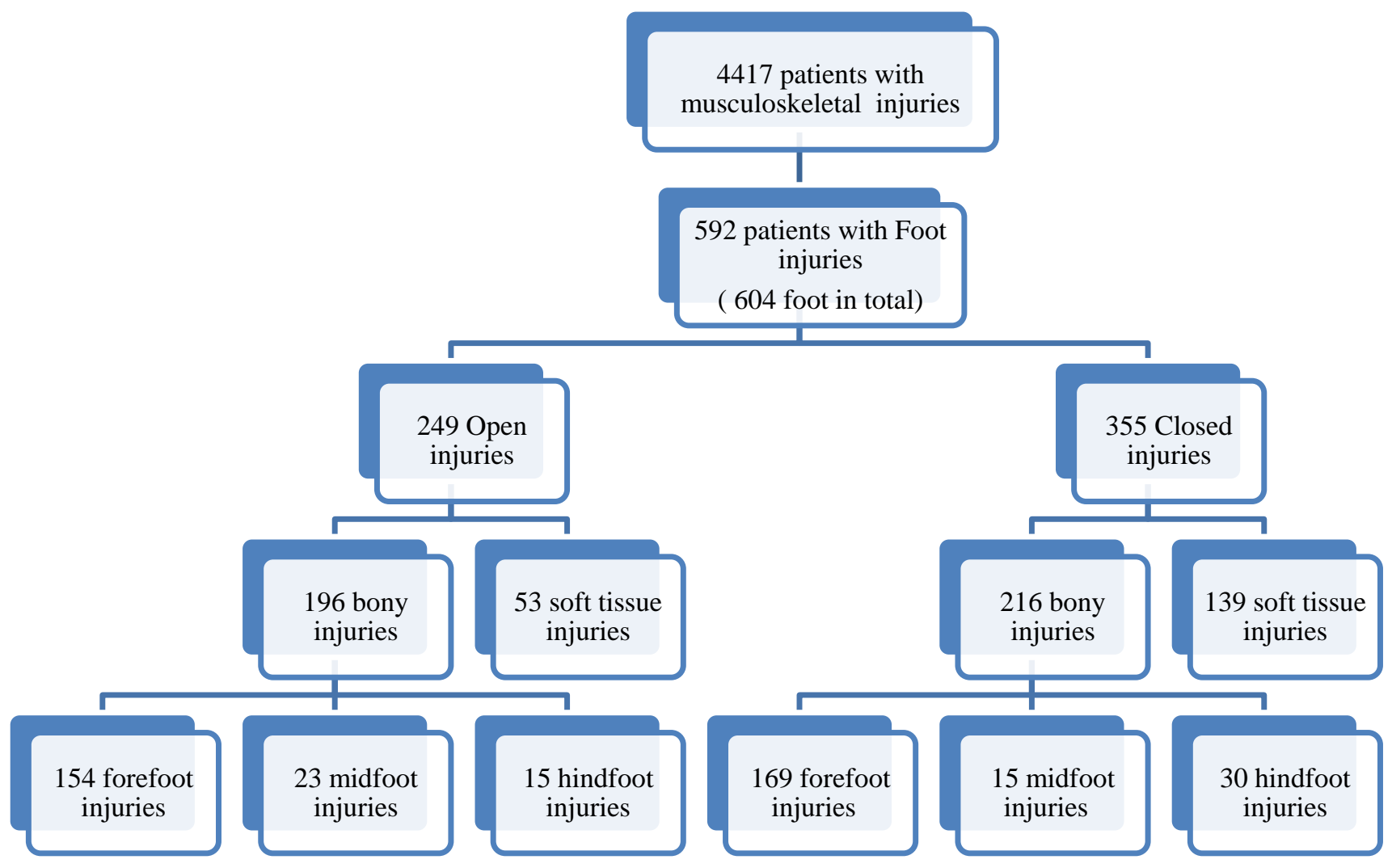

Figure 3: The distribution of patients with foot injuries. 


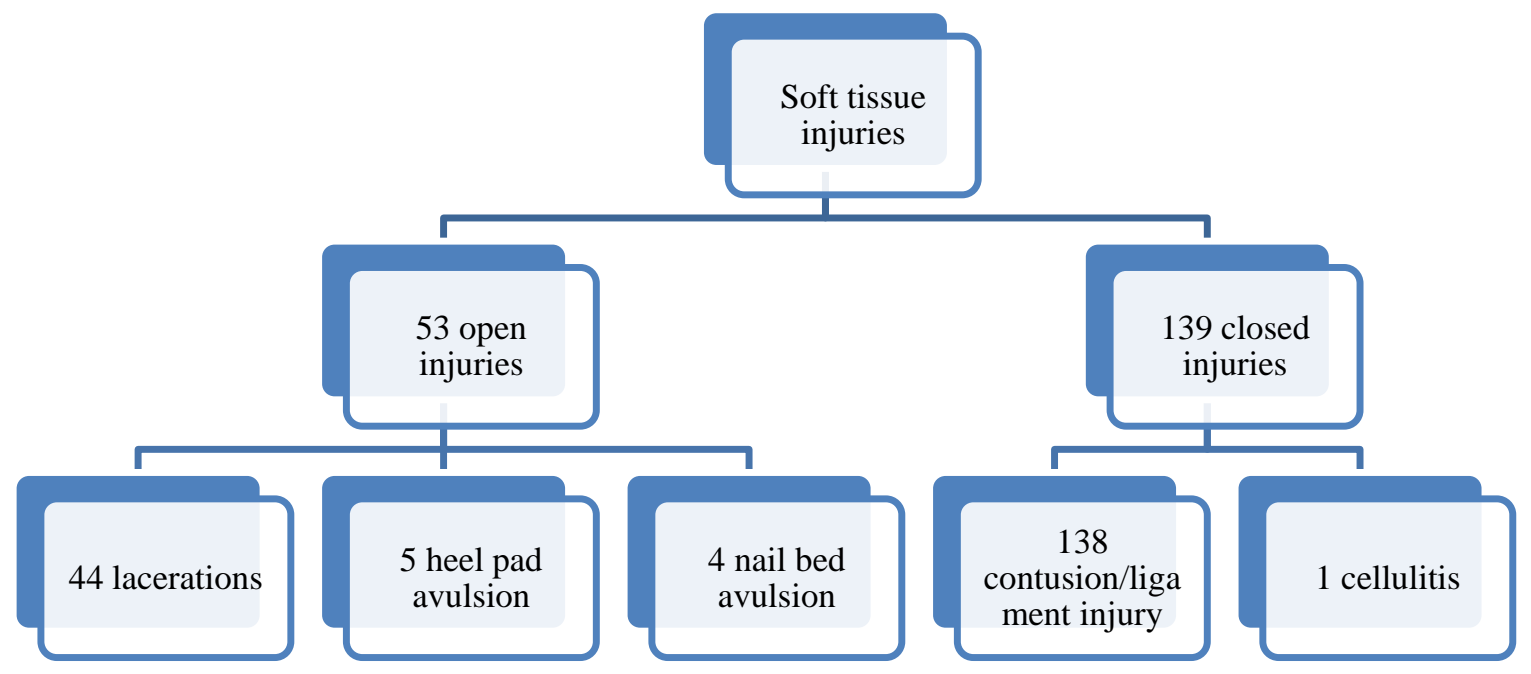

Figure 4: The distribution of soft tissue injuries.

Table 2: Distribution of forefoot injuries.

\begin{tabular}{|llllll|}
\hline Injury type & Bone involved & Open & Closed & Total & Percentage \\
\hline Fracture & Proximal phalanx & 30 & 33 & 63 & 19.5 \\
\hline & Middle phalanx & 3 & 3 & 6 & 1.9 \\
\hline & Distal phalanx & 12 & 7 & 19 & 5.8 \\
\hline & Metatarsal & 35 & 105 & 140 & 43.3 \\
\hline & Combined (multiple phalanx or phalanx and metatarsal & 21 & 14 & 35 & 10.8 \\
\hline $\begin{array}{l}\text { Amputation/crush } \\
\text { injuries }\end{array}$ & & 11 & 7 & 18 & 5.6 \\
\hline Total & & 42 & 0 & 42 & 13.1 \\
\hline
\end{tabular}

Table: 3 Distribution of metatarsal injuries.

\begin{tabular}{|llll|}
\hline Metatarsal involved & Open & Closed & Total \\
\hline $\mathbf{1}$ & 3 & 7 & 10 \\
\hline $\mathbf{2}$ & 3 & 10 & 13 \\
\hline $\mathbf{4}$ & 3 & 8 & 11 \\
\hline $\mathbf{5}$ & 0 & 5 & 5 \\
\hline Multiple & 6 & 35 & 41 \\
\hline Total & 20 & 40 & 60 \\
\hline
\end{tabular}

Table 4: Distribution of midfoot injuries.

\begin{tabular}{|lllllll|}
\hline Injury type & Bone involved & Open & Closed & Total & Percentage \\
\hline Fracture & Navicular & 2 & 4 & 6 & 15.8 \\
\hline & Cuboid & 1 & 3 & 4 & 10.5 \\
\hline & Cuneiform & 3 & 3 & 6 & 15.8 \\
\hline Fracture- dislocation & Combined & 1 & 0 & 1 & 2.6 \\
\hline & Lisfranc injury & 8 & 4 & 12 & 31.6 \\
\hline Amputation/crush injuries & Chopart injury & 2 & 1 & 3 & 7.9 \\
\hline
\end{tabular}




\begin{tabular}{|lllll|}
\hline Total & 23 & 15 & 38 & 100 \\
\hline
\end{tabular}

Table 5: Distribution of hindfoot injuries.

\begin{tabular}{|llllll|}
\hline Injury type & Bone involved & Open & Closed & Total & Percentage \\
\hline Fracture & Talus & 3 & 8 & 11 & 24.4 \\
\hline & Calcaneum & 9 & 18 & 27 & 60.1 \\
\hline & Combined & 0 & 2 & 2 & 4.4 \\
\hline Fracture- dislocation & & 1 & 2 & 3 & 6.7 \\
\hline Amputation/crush injuries & & 2 & 0 & 2 & 4.4 \\
\hline Total & & 15 & 30 & 45 & 100 \\
\hline
\end{tabular}

Of the 140 metatarsal injuries, 80 were isolated injuries. 12 were open fractures and the rest were closed injuries. Fifth metatarsal injuries were the most common among isolated metatarsal fractures accounting for 41 cases. 60 were multiple metatarsal injuries. 20 out of these 60 cases had open injuries (Table 3). Among the midfoot injuries, Lisfranc fracture dislocation was more common accounting for 12 out of 38 cases (Table 4).

Calcaneal fractures were more common among hindfoot injuries accounting for 27 out of 45 cases (Table 5). Six cases had combined midfoot and forefoot injuries. Out of these six cases, four were open and two were closed injuries.

\section{DISCUSSION}

Foot injuries range from simple sprain to complex fracture dislocations, crush injury and traumatic amputation. These foot injuries, if managed inadequately can lead to significant morbidity in terms of function, cosmesis and psychological impact. With the increase in motor vehicle accidents in the present scenario, it is important to know the various patterns of presentation of foot injuries. Injury patterns vary widely among countries due to difference in race, location, socioeconomic status and industrialisation. In India, barefoot walking is very common and hence incidence and severity of the injury is also high compared to western population. There is paucity of literature regarding epidemiology of foot injuries in India. Only one study has been published so far from Northern part of the country. ${ }^{4}$ Hence, in this study we have discussed the epidemiological pattern of foot injuries in South India.

In our study, out of 4417 patients who presented to our hospital in one year, we had 592 patients with foot injuries (604 foot involved as 12 patients had bilateral involvement). Therefore, foot injuries accounted for $13.4 \%$ of total musculoskeletal injuries. This is almost double compared to $7.59 \%$ reported by Dhillon et al in their study on North Indian population and $6.64 \%$ reported by Tadros et al in their study in high income country. ${ }^{4,6}$ The incidence is high probably because of rapid urbanization along with increase in the number of high speed vehicles leading to road congestion and increase in accidents. Jeffer et al reported an incidence of $4.3 \%$ of foot injuries among motorcyclists while Hasselman et al reported an incidence of 3.1 per 1000 cases among elderly white women.,

The mean age in our study was 32.09 years (Range: 2 -76 years). There were 461 male and 131 female patients. $31.7 \%$ were in the age group 21-30 years followed by $19.6 \%$ of patients between the age group 31- 40 years. Age group between 20-40 years is the most physically and socially active group in any country and this is their active phase of earning for themselves and for their family. Hence, any morbidity following foot injury will definitely affect their occupation and also their active life. Again, male population have got more injuries compared to female population $(77.8 \%$ Vs $22.2 \%)$ in our study. This is because in a developing country like India, mostly males are the bread winners for their family. They are commonly involved in outdoor activities including driving vehicles for long distance which predisposes them to road traffic injuries.

There were $357(60.3 \%)$ patients had injury following road traffic accident followed by 112 (18.9\%) patients who sustained accidental fall. Rapid urbanisation along with overspeeding, poor maintenance of vehicles and roads and general disregard for road safety rules have led to rise in road traffic injuries in our country. Dhillon et al reported $73.88 \%$ of foot injuries after RTA and $20.15 \%$ sustained accidental fall. ${ }^{4}$ Shibuya et al from United States reported that $53.49 \%$ occurred in the road followed by $26.12 \%$ at home. ${ }^{5}$ Tadros et al in their study in high income country reported fall from height as the most common mechanism of injury. ${ }^{6}$ Petrisor et al in their study on metatarsal injuries reported twisting injury as the most common mechanism for metatarsal fractures. ${ }^{7}$ Richter et al did a study on mechanism of foot injury in front seat occupants and found that the injuries occur due to foot compartment deformation during head-on collisions. ${ }^{8}$ The mechanism of injury is very important as it dictates the distribution of injuries.

Out of 604 feet involved, 249 (41.2\%) of them sustained open injuries while the rest $355(58.8 \%)$ had closed 
injuries. 192 of them had only soft tissue injuries of which 53 had open injuries and 139 cases had closed injuries. Among open injuries, laceration of the foot was seen in 38 feet followed by tendon injury in 6 , heel pad avulsion in 5 and nail bed avulsion in 4.138 out of 139 closed injuries sustained soft tissue injuries in the form of contusion and ligament injury while one patient presented with cellulitis. Dhillon et al reported $72.39 \%$ of open fractures and $23.13 \%$ of closed fractures. ${ }^{4}$ Soft tissue injuries accounted for $12 \%$ in the study by Tadros et al in United Arab. ${ }^{6}$

Among the 412 bony injuries, forefoot injuries were more common accounting for 323 followed by hindfoot injuries with 45 and midfoot injuries with 38 . The injury pattern was similar to Dhillon et al study who reported 94 cases of forefoot injuries followed by 60 cases of hindfoot injuries and 23 cases of midfoot injuries. ${ }^{4}$ The pattern differs from that of high income country report where hindfoot injuries accounted for $56 \%$ and forefoot injuries accounted for $32 \%$. This is probably because their most common mechanism of injury was fall from height and hence hindfoot was more prone for fractures. 140 out of 323 cases of forefoot injuries were due to metatarsal fractures followed by 63 cases of proximal phalanx fractures. Shibuya et al also reported that metatarsal injuries are more common than phalanx injuries in their population. ${ }^{5}$ Jeffer et al reported $49.1 \%$ of metatarsal injuries among motorcyclists. ${ }^{2}$ Hasselman et al reported $88.5 \%$ of metatarsal injuries among elderly white women. ${ }^{3}$ Petrisor et al in their study reported fifth metatarsal $(68 \%)$ as the most common bone fractured among metatarsals. ${ }^{7}$ Childers et al and Hasselman et al in their study also reported that fifth metatarsal was the most common injured metatarsal. ${ }^{9,3}$ In our study, combined metatarsal injuries were more compared to isolated metatarsal injuries. Among isolated metatarsal injuries, fifth metatarsal was most common and accounted for $29.3 \%$.

Among the midfoot injuries, Lisfranc fracture dislocation was more common accounting for 12 out of 38 cases. Dhillon et al reported 12 cases of Lisfranc injuries among 23 cases of midfoot injuries. ${ }^{4}$ Among hindfoot injuries, calcaneal fractures were more common accounting for 27 out of 45 cases which is also similar to Dhillon et al who reported 45 out of 60 cases. $^{4}$ Out of 27 cases of calcaneal injuries, nine $(33.3 \%)$ were open. In Dhillon et al series, open calcaneal injuries accounted for $46.67 \%$ which is slightly higher than our study. ${ }^{4}$ Tadros et al reported $2 \%$ of open calcaneal injuries. ${ }^{6}$

We were unable to collect data about the use of protective footwear, type of vehicle involved, actual speed of the vehicle at the time of accident and the road conditions which would have added more details to the current study as certain preventive measures and awareness could have been created based on the data.
This study highlights the epidemiological pattern of foot injuries in Indian scenario. These are the number of cases which has come to a tertiary referral centre. Actual number of injuries might be much more as isolated foot injuries might be treated at a nearby local hospital. Also there will be missed foot injuries and neglected injuries which are not included.

The limitation of our study is it is a retrospective study. We have not assessed the severity of injuries, the timing of surgery, type of treatment and outcomes.

\section{CONCLUSION}

To conclude, foot injuries account for $13.4 \%$ of all musculoskeletal injuries. $51.3 \%$ are between $20-40$ years age group. Closed injuries are more common than open injuries. $68.2 \%$ accounts for bony injuries. Among foot bony injuries, forefoot injuries $(78.4 \%)$ are more common. Metatarsal fractures $(43.3 \%)$ are common in forefoot injuries. Lisfranc injuries are more common among midfoot injuries and calcaneal injuries are more common among hindfoot injuries. A prospective study including treatment of foot injuries and long term followup will shed more light on the importance of these injuries.

\section{Funding: No funding sources \\ Conflict of interest: None declared \\ Ethical approval: The study was approved by the institutional ethics committee}

\section{REFERENCES}

1. Pearce CJ, Brooks JH, Kemp SP, Calder JD. The epidemiology of foot injuries in professional rugby union players. Foot ankle Surg. 2011;17(3):113-8.

2. Jeffers RF, Tan HB, Nicolopoulos C, Kamath R, Giannoudis PV. Prevalence and patterns of foot injuries following motorcycle trauma. J Orthopaedic Trauma.2004;18(2):87-91.

3. Hasselman CT, Vogt MT, Stone KL, Cauley JA, Conti SF. Foot and ankle fractures in elderly white women: incidence and risk factors. JBJS. 2010;85(5):820-4.

4. Dhillon MS, Aggarwal S, Dhatt S, Jain M. Epidemiological pattern of foot injuries in India: preliminary assessment of data from a tertiary hospital. J Postgraduate Medicine Education Res. 2012;46(3):144-7.

5. Shibuya N, Davis ML, Jupiter DC. Epidemiology of foot and ankle fractures in the United States: an analysis of the National Trauma Data Bank. J Foot Ankle Surg. 2007-2011;53(5):606-8.

6. Tadros AM, Eid HO, Abu-Zidan FM. Epidemiology of foot injury in a high-income developing country. Injury. 2012;41(2):137-40.

7. Petrisor BA, Ekrol I, Court-Brown C. The epidemiology of metatarsal fractures. Foot \& ankle international. 2006;27(3):172-4. 
8. Richter M, Thermann H, Wippermann B, Otte D, Schratt HE, Tscherne H. Foot fractures in restrained front seat car occupants: a long-term study over twenty-three years. J Orthop Trauma. 2001;15(4):287-93.

9. Childers Jr RL, Meyers DH, Turner PR. Lesser metatarsal stress fractures: a study of 37 cases. Clin Podiatr Med. Surg. 1990;7:633-44.
Cite this article as: Balaji G, Nema S, Kumar A. A study on epidemiology of foot injuries in South Indian population at a tertiary care centre. Int J Res Orthop 2020;6:1063-9. 